\title{
Revisión
}

\section{Gripe aviar: lo que un intensivista debe conocer}

\author{
S. CASILLAS ${ }^{a}$, S. HERRERO FERNÁNDEZ ${ }^{b}$ Y J. VARONº \\ aUniversidad Autónoma de Baja California. México. \\ bServicio de Medicina Intensiva y Unidad Coronaria. Fundación Medicina Intensiva-Gijón. \\ Hospital de Cabueñes. Gijón. Asturias. España. \\ 'The University of Texas Health Science Center of Houston. St. Luke's Episcopal Hospital. \\ The University of Texas Medical Branch at Galveston and Houston. Texas. EE. UU.
}

En el siglo pasado, la humanidad ha hecho frente a tres de las mayores pandemias de infecciones por el virus de la gripe. La primera fue en 1918, y causó una cantidad significativa de muertes. Éste ha sido también capaz de cruzar la barrera de la especie y afectar a los mamíferos y, lo más preocupante, a los seres humanos. Desde entonces se han publicado varios brotes en el sudeste de Asia. Una gran cantidad de pacientes presenta un curso severo que desarrolla neumonía y disfunción, que implica al hígado, los riñones, el cerebro y los pulmones.

Puesto que el virus carece de control regulador de la división genética, experimenta mutaciones constantes que conducen a nuevos subtipos y a nuevas cepas. Los únicos fármacos que han mostrado cierta protección son oseltamivir y zanamivir. Es crucial desarrollar vacunas eficaces y no costosas para prevenir la extensión del virus y la infección, no solamente en seres humanos sino también en aves.

PALABRAS CLAVE: gripe aviar, fallo respiratorio agudo, virus H5N1, neuraminidasa, oseltamivir.

\section{BIRD FLU: WHAT THE INTENSIVIST MUST KNOW}

In the last century, humankind has faced 3 major pandemics of influenza virus infections. The first one occurred in 1918 and caused a significant

Correspondencia: Dr. J. Varon.

2219 Dorrington.

77030 Houston. Texas. EE. UU.

Correo electrónico: joseph.varon@uth.tmc.edu

Manuscrito aceptado el 28-V-2007. amount of deaths. It was also capable of crossing over species barrier and affecting mammals, and most worrisome, humans. Since then several outbreaks have been reported in the Southeast of Asia. Many patients with the flu-like illness have a severe course and the patient develops pneumonia and in some cases multiorgan failure involving liver, kidneys, brain and lungs.

Since the virus lacks regulatory control of genetic division it undergoes constant mutations leading to new subtypes and, sometimes, new strains. The only drugs that have shown some protection are oseltamivir and zanamivir. It is crucial to develop effective and non-expensive vaccines to prevent the virus spread and infection not only in humans but in birds too.

KEY WORDS: aviar flu, acute respiratory failure, H5N1 virus, neuroaminidase, oseltamivir.

\section{INTRODUCCIÓN}

Una de las infecciones respiratorias más comunes es causada por el virus de la gripe ${ }^{1}$. La gripe ha estado presente durante siglos y la relación cercana con ella ha dado lugar a epidemias anuales con patrones estables demográficos y de morbimortalidad ${ }^{2}$. Cada 20-30 años aparece una nueva pandemia, con elevada mortalidad ${ }^{3,4}$. Todas las epidemias importantes de la gripe en seres humanos han sido causadas por los virus de la gripe de origen aviar ${ }^{3}$. El brote más importante fue el brote español de la gripe aviar en $1918^{5}$.

En 1997 se identificaron en Hong-Kong varios casos de infección del tracto respiratorio superior en se- 
res humanos ${ }^{6}$. El progreso de la infección fue refractario a muchas formas de aproximación terapéutica y usualmente era letal. El agente causal fue un virus, sorprendentemente un virus de la gripe, y asombrosamente era un novedoso virus de la gripe aviar (gripe aviar altamente patógena H5N1), el cual desempeñaba el papel principal en esta ocasión ${ }^{6}$. Para controlar esta infección los criadores rurales sacrificaron más de 100 millones de pájaros ${ }^{7}$.

Tras este episodio se han presentado varios brotes en muchos países de Asia suroriental, tales como China, Vietnam, Camboya, Tailandia, Laos, Corea del sur, Japón, Hong-Kong e Indonesia ${ }^{7,8}$. Con fecha del 29 de noviembre de 2006, se han identificado 258 casos de la gripe aviar H5N1 en seres humanos y 154 personas han muerto?.

\section{RECONOCIMIENTO HISTÓRICO DE LA GRIPE Y DE LA GRIPE AVIAR}

Los virus de la gripe son propensos a variaciones genéticas continuas o rápidas ${ }^{10}$. El reservorio principal de los virus de la gripe son las especies de pájaros acuáticos, tales como patos o gansos. La asociación virus-pájaros es antigua y de ahí que el pájaro esté perfectamente adaptado a la presencia parásita del virus. Tras introducirse en un nuevo huésped, el virus, especialmente los subtipos $\mathrm{H} 5$ y H7, experimenta un inicio rápido de cambios y se desarrolla en nuevas isoformas o virus nuevos que sean más patógenos ${ }^{7,11}$.

La gripe fue inicialmente identificada en Italia en $1878^{12}$. En 1918 Europa fue el escenario principal para una de las pandemias más terribles conocida por los hombres, la gripe española, también conocida como «la madre de las pandemias» ${ }^{5}$. La voracidad devastadora de este virus afectó a casi un tercio de la población humana, es decir, a 500 millones de personas, matando alrededor de 100 millones de personas ${ }^{5,13}$. Esta pandemia provocó más muertes que la Primera y la Segunda Guerra Mundial juntas ${ }^{14} \mathrm{y}$ fue causada por el subtipo H1N1 del virus de la gripe A.

Este virus continúa siendo mortal a pesar de los muchos esfuerzos que se han llevado a cabo para ordenar el genoma viral aislado en $1995^{15}$. Un hecho interesante es que afectó a seres humanos y a cerdos simultáneamente ${ }^{16,17}$, lo que condujo a pensar que el cerdo es un portador intermedio de ambas gripes de los tipos aviar y humana. Mató al 50\% de los adultos de 15 a 34 años que lo contrajeron. La tasa de mortalidad fue del 2,5\% en Estados Unidos ${ }^{18}$.

Los estudios virológicos actuales han probado que este virus era enteramente nuevo para los seres humanos y se ha sugerido que su origen pudo haber sido aviar $^{19}$. Las epidemias de 1957, 1968 y 1977 estaban todas relacionadas directamente con esa primera epidemia y consistían en los virus que experimentaron la deriva genética/antigénica: H1N1, H2N2 o el reajuste $\mathrm{H} 3 \mathrm{~N} 2$, y todos ellos se han encontrado desde entonces en pájaros en $\mathrm{Asia}^{20}$.

Los primeros casos de la infección aviar altamente patógena de la gripe H5N1 en seres humanos fueron documentados por primera vez en Hong-Kong, cuando apareció un brote de 18 casos $^{6}$. El inicio de la enfermedad era rápido y el curso clínico era severo: alcanzaba altas cotas de mortalidad (el 33\%) y desarrolló neumonía en casi todos estos pacientes y en algunos casos disfunción múltiple de órganos ${ }^{6}$.

\section{EPIDEMIOLOGÍA}

Un 20\% de los niños y un 5\% de los adultos tienen infección sintomática de la gripe humana cada año ${ }^{21}$. En una estación media en los Estados Unidos, la gripe causa más de 30.000 muertes y más de 100.000 hospitalizaciones ${ }^{22,23}$.

El primer brote de virus aviar de la gripe $\mathrm{H} 5 \mathrm{~N} 1$ en seres humanos se desarrolló en Hong-Kong ${ }^{6}$. Se asoció con la enfermedad humana la exposición a las aves de corral vivas una semana antes del inicio de la enfermedad $^{24,25}$. La vigilancia serológica demostró la evidencia de infecciones asintomáticas después del contacto en casos humanos ${ }^{26}$.

Desde 2003 un virus aviar altamente patógeno (gripe A H5N1) ha explotado entre las aves de corral, distribuyéndose por lo menos por 9 países de Asia (Camboya, China, Indonesia, Japón, Laos, Malasia, Corea del Sur, Tailandia y Vietnam $)^{8}$.

Antes de 2004 en Asia suroriental se documentaron muchos informes de la gripe aviar (H5N1), principalmente en Vietnam, Tailandia e Indonesia. Por enero de 2004, el virus aviar altamente patógeno de la gripe (HPAI) del subtipo $\mathrm{H} 5 \mathrm{~N} 1$ fue primero confirmado en aves de corral y en seres humanos en Tailandia ${ }^{27}$. Los estudios a principios de 2004 demostraron que los patos fueron los principales portadores silenciosos del virus de $\mathrm{HPAI}^{28,29}$. En 2003 en Tailandia se detectaron los primeros casos en humanos del virus $\mathrm{H} 5 \mathrm{~N} 1^{30}$.

Desde 2004 se han documentado 254 casos de infección humana por el virus aviar de la gripe H5N1 en Asia y han muerto 150 pacientes, conduciendo a un índice de mortalidad de casi el 60\%. La mayoría de los casos humanos ocurrieron en Vietnam e Indonesia9 . Aunque la transmisión directa del virus de pollos a los seres humanos es preocupante, aún es mayor que la transmisión entre humanos pueda comenzar a ocurrir. La epidemia todavía está en curso. La transmisión de humano a humano de la gripe A (H5N1) se ha sugerido en varios grupos y en un caso de transmisión evidente de niño a madre ${ }^{31}$. Aunque el virus H5N1 está apuntando a la población humana, la infección entre humanos no ha sido demostrada consistentemente y hay muchos informes probados de que esta infección no se ve transmitida entre huma$\operatorname{nos}^{32,33}$. La controversia viene con algunos otros estudios que sugieren que el contacto cercano entre personas pueda conducir a la infección aviar de la $\operatorname{gripe}^{31,34}$.

Más de 258 casos de infección aviar de la gripe H5N1 en seres humanos por todo el mundo han sido documentados por la Organización Mundial de la Salud a partir de 2003 hasta el 29 de noviembre de $2006^{9}$ (tabla 1 y fig. 1 ). 
TABLA 1. Número total de casos incluyendo el número de muertes a 6 de febrero de 2007

\begin{tabular}{|c|c|c|c|c|c|c|c|}
\hline País/año & 2003 & 2004 & 2005 & 2006 & 2007 & Total casos & Total muertes \\
\hline Indonesia & 0 & 0 & 19 & 56 & 6 & 81 & 63 \\
\hline Tailandia & 0 & 17 & 5 & 3 & & 25 & 17 \\
\hline China & 1 & 0 & 8 & 13 & & 22 & 14 \\
\hline Egipto & 0 & 0 & 0 & 18 & 2 & 20 & 12 \\
\hline Camboya & 0 & 0 & 4 & 2 & & 6 & 6 \\
\hline Acerbayán & 0 & 0 & 0 & 8 & & 8 & 5 \\
\hline Turquía & 0 & 0 & 0 & 12 & & 12 & 4 \\
\hline Iraq & 0 & 0 & 0 & 3 & & 3 & 2 \\
\hline Yibuti & 0 & 0 & 0 & 1 & & 1 & 0 \\
\hline Vietnam & 3 & 29 & 61 & 0 & & 93 & 42 \\
\hline Nigeria & 0 & 0 & 0 & 0 & 1 & 1 & 1 \\
\hline Total & 4 & 46 & 97 & 116 & & 272 & 166 \\
\hline
\end{tabular}

La Organización Mundial de la Salud sólo publica los casos confirmados por laboratorio. Número acumulativo de casos humanos confirmados de gripe aviar A/(H5N1). Reported to World Health Organization.

\section{VIROLOGÍA}

Los virus A, B y C de la gripe son los tres géneros principales de la familia Orthomyxovirida ${ }^{10,35}$. Estos tres tipos se clasifican en función de las proteínas de su núcleo (NP y M) $)^{34}$. La gripe A infecta mamíferos y pájaros mientras que la $\mathrm{B}$ y la $\mathrm{C}$ se restringen a los seres humanos ${ }^{36,37}$.

La gripe A tiene dos tipos de glucoproteínas de la superficie de su membrana que determinan el subtipo: hemaglutinina y neuraminidasa. Hay 16 tipos de hemaglutininas y 9 tipos de neuraminidasas ${ }^{38}$. La he- maglutinina es el blanco viral principal de la inmunidad humoral protectora, ya que neutraliza los anticuerpos; y está también a cargo de la conexión viral a la membrana de la célula y ayuda a su entrada en las células huésped, vinculando a los receptores del ácido siálico en la superficie ${ }^{39}$. La glucocoproteína hemaglutinina es producida por un precursor, el HA0, el cual requiere división post traductora (posttranslational cleavage) de las proteasas del huésped principal ${ }^{40}$. La división del precursor HA0 en virus de HPAI es catalizada solamente por la tripsina y proteasas similares a la tripsina (trypsin-like) del huésped principal,

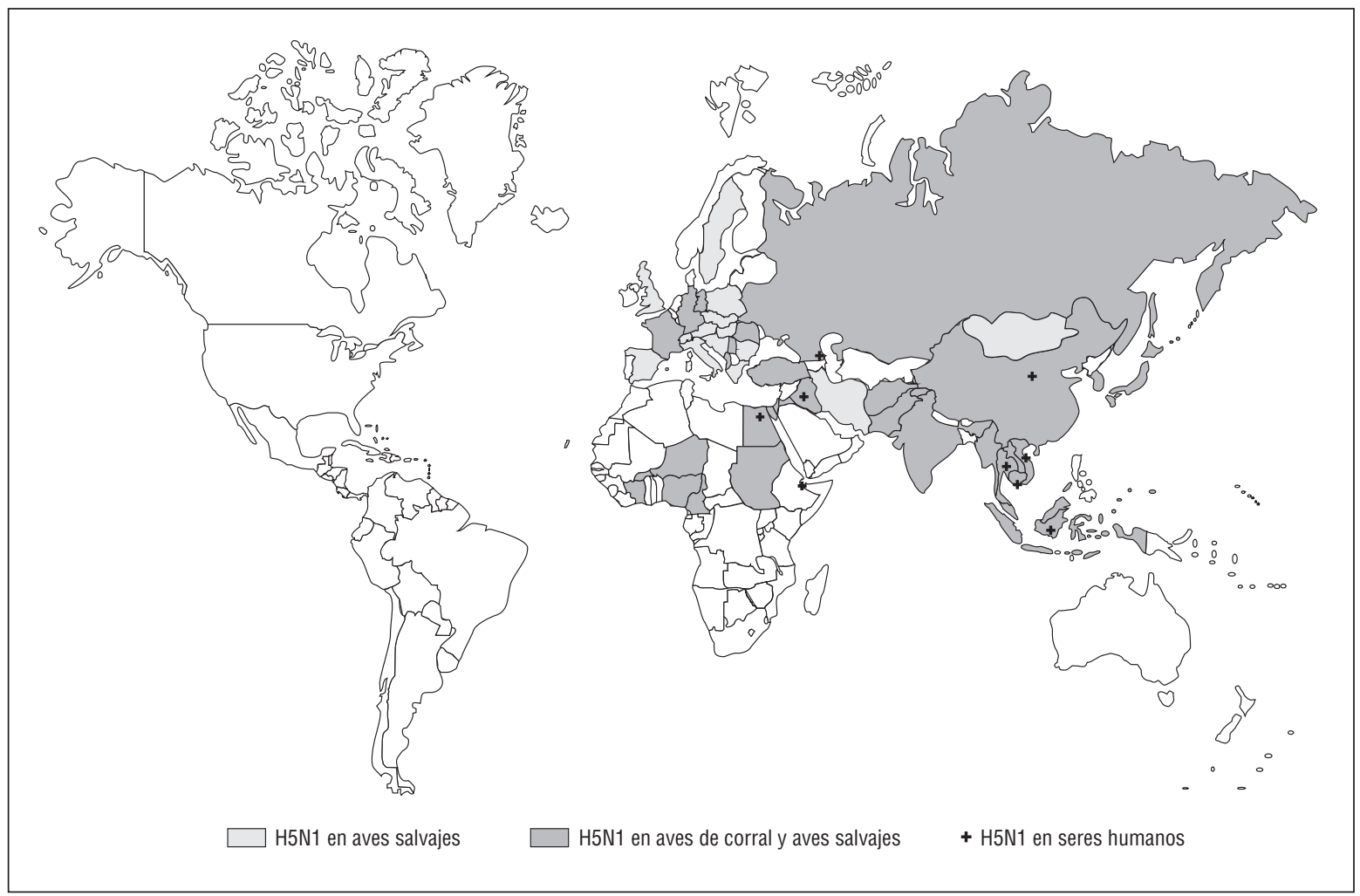

Figura 1. Países afectados por el virus de la gripe aviar H5N1. Infección en pájaros salvajes, aves de corral y humanos hasta febrero de 2007. Fuente: www.pandemicflu.com 
tales como la ubicua furina y la proteasa relacionada clara-cell, limitando al virus a las localizaciones donde se encuentran estas proteasas, a saber, a las zonas respiratorias e intestinales ${ }^{41}$.

Los virus humanos atan preferencialmente al ácido siálico unidos a galactosa por acoplamientos «alfa 2-6», que son el tipo principal encontrado en las células epiteliales de la zona respiratoria humana ${ }^{39}$. Los virus aviares tienen acoplamientos «alfa 2-3», principalmente en el intestino, por lo tanto la transmisión horizontal entre pájaros se hace por materia fecal, mientras que la transmisión horizontal en seres humanos es proporcionada por la exposición de la zona respiratoria y de la mucosa asociada, tal como la oral, nasal y conjuntival a las partículas virales ${ }^{42}$.

La neuraminidasa, por otra parte, es una proteína tetramérica que facilita la extensión de viriones en el huésped principal, cortando los residuos del ácido siálico que están presentes en los mucopolisacáridos de la superficie celular y facilitando la conexión de la hemaglutinina a los receptores celulares ${ }^{43}$.

El genoma de la gripe A consiste de 8 únicos segmentos inmóviles de ARN trenzado apilados en el lípido que envuelve a los viriones ${ }^{10}$. Los 8 segmentos del ARN del genoma del virus de la gripe A codifican 11 proteínas, que son: cuatro proteínas polimerasas (PB1, PB2, PA, PB1-F2), una proteína de la nucleocápside, una hemaglutinina, una neuraminidasa, dos proteínas de la matriz (M1, M2) y dos proteínas no estructurales (NS1, NS2) ${ }^{42}$. Un solo segmento del ARN codifica dos proteínas de la matriz: M1 y M2. La M1 está situada debajo de la doble capa del lípido del virus y es interna. La M2 funciona como un canal iónico que domina una pequeña superficie extracelular y es el objetivo de los fármacos antivíricos amantidina y rimantidina ${ }^{10,44}$. Otro segmento del ARN consiste en el gen no estructural (NS), que codifica NS-1 y la proteína nuclear exportadora (NEP). La NS-1 ayuda a las partículas virales neutralizando interferones (IFN). La NEP está implicada en la exportación nuclear del ARN y del ensamblaje viral. Los cuatro segmentos restantes del ARN codifican simples proteínas internas, a saber la PB1, la PB2, la polimerasa PA implicada en la transcripción gen viral y la nucleoproteína (NP) que encapsida los segmentos genómicos ARN. La PBF2 conduce a la apoptosis de la célula y afecta principalmente a las mitocondrias ${ }^{45}$.

\section{¿ENMASCARADO O CAMBIANDO LAS CARAS?}

Es curioso que un defecto evolutivo en la réplica genómica del control de calidad de los virus por el complejo ARN-dependiente «virus-codificado» de la polimerasa del ARN sea relativamente propenso a errores y a estas mutaciones en el genoma ARN, que son la mayor fuente de variaciones genéticas por la deriva antigénica ${ }^{46}$. Cuando existe cierta cantidad acumulada de mutaciones genéticas de menor importancia y el virus adquiere nuevas características superficiales, tales como una alteración en la estructura de la hemaglutinina, decimos que el virus está «de- senfundando una máscara», puesto que el cambio principal estaba simplemente en la superficie; llamamos a ese proceso de deriva antigénica. Este mecanismo permite a los virus reinfectar previamente a huéspedes expuestos y evadir un «sistema inmune ingenuo» que lo reconoció previamente. Este fenómeno se proyecta como epidemias anuales, puesto que el virus usa una «nueva máscara» cada año $0^{5,12}$.

\section{MECANISMO DE EXTENSIÓN}

Las rutas principales de transmisión de la gripe humana son la inhalación de gotitas y de núcleos infecciosos de la gotita, el contacto directo y, quizás, el contacto indirecto (vómito), con auto-inoculación sobre la zona respiratoria superior o la mucosa conjuntival $^{47,48}$.

Los virus de la gripe han encontrado su principal reservorio en las aves acuáticas salvajes (por ejemplo, patos y gansos $)^{14,49}$. Parece que los pájaros están muy bien adaptados a la presencia permanente del virus debido al hecho de que la coexistencia no es patológica en la mayoría de los casos y no conduce a ninguna manifestación de la enfermedad o da muestras de infección ${ }^{49,50}$. El intestino aviar es el órgano que tienen la mayoría de los receptores específicos para las partículas del virus aviar (ácido siálico-alfa $2-3)^{42}$. Estos receptores en el intestino permiten una réplica viral continua y separarse junto con la materia fecal producida. Por lo tanto, el ambiente, principalmente los humedales, lagos y ríos, donde es predominante la presencia de patos, gansos y otras aves acuáticas, facilita la exposición a las partículas virales ${ }^{36}$. La migración de pájaros salvajes propaga la infección entre las especies de pájaros y la extensión de nuevos tipos de virus a los terrenos de la ingenuidad inmunológica, en donde se produce la infección rápida de pájaros y la manifestación de la enfermedad ${ }^{51-53}$. La migración ha diseminado la infección H5N1 entre Asia, Europa y África (figs. 1 y 2). Los criadores rurales, y el personal que trabaja con las aves de corral y sus desechos, son las poblaciones humanas principalmente expuestas ${ }^{54}$.

Otra característica especial en la gripe aviar es que tiene receptores en otras especies mamíferas, como en los cerdos ${ }^{16,17,42}$. Esto es muy preocupante, ya que el cerdo es muy común en la dieta humana y se encuentra habitualmente en contacto cercano a las poblaciones humanas ${ }^{55}$.

La transmisión entre humanos de la gripe aviar altamente patógena es la preocupación principal. Aunque existen varios estudios entre trabajadores sanitarios expuestos a pacientes infectados ${ }^{26,33,34,56,57}$, la mayoría de los casos humanos señalados se correlacionan directamente con el contacto cercano a las aves de corral enfermas o que mueren ${ }^{25}$.

\section{PATOGÉNESIS}

El tropismo tisular y la respuesta inmunológica exagerada al virus desempeñan los dos papeles prin- 


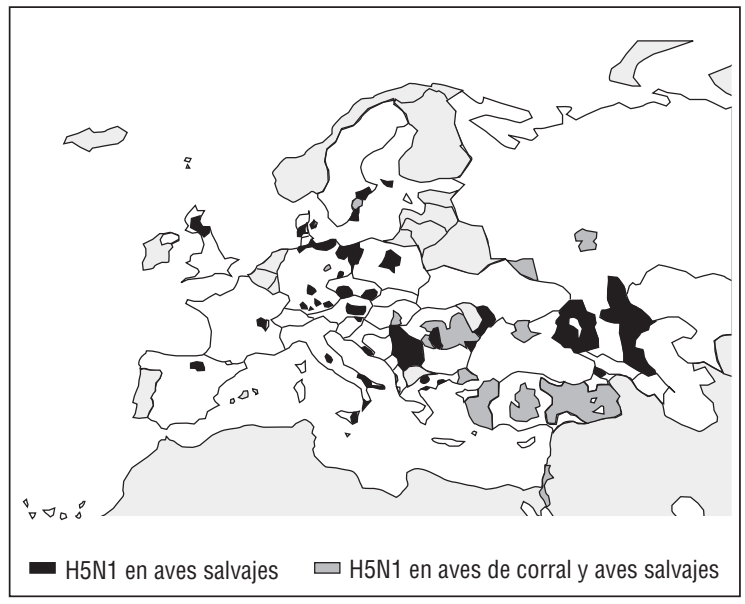

Figura 2. Presencia de la gripe aviar altamente patógena H5N1 en países europeos desde el 1 de julio de 2005 hasta el 6 de octubre de 2006. Fuente: www.euro.who.int/document/INF/Map_EURO_ SubNat_H5N1inAnimal ConfirmedCUMULATIVE_20061006.p $\overline{d f}$

cipales en la configuración de la enfermedad ${ }^{58}$. Los virus altamente patógenos de la gripe, tales como el H5N1, tienen capacidad de replicarse pobremente en tejidos enriquecidos con proteasas en el organismo ${ }^{59}$. Esto permite que el virus produzca copias de sí mismo extensamente en diferentes partes del cuerpo, propiciando una reacción generalizada.
Tras la entrada del virus de la gripe aviar H5N1, a través de la vía respiratoria superior, se acciona la inmunorrespuesta (no específica) natural y la detección inmediata del virus se hace a través de los receptores tipo toll-like que se encuentran en los neutrófilos y los macrófagos residentes en el epitelio del pulmón y de la zona respiratoria ${ }^{60,61}$.

De forma temprana, durante el primer contacto con el virus se libera una gran cantidad de citoquinas proinflamatorias para luchar contra el agresor (figs. 3 y 4).

Entre éstas, el IFN tipo I, el factor de necrosis tumoral alfa y la interleuquina 12 son las sustancias más importantes implicadas en la activación aguda de la inmunorrespuesta natural ${ }^{62,63}$. Esta fase es constante con el cuadro de inicio agudo de la enfermedad respiratoria, por ejemplo, neumonía severa seguida por fallo multiorgánico en algunos pacientes infectados con gripe aviar HPAI H5N1 que comienzan previamente con enfermedad gripa ${ }^{31,64}$. Tras esta cascada de acontecimientos, los fagocitos engullen las partículas virales y actúan como presentadores del antígeno a las células-B situadas principalmente en el bazo, los nódulos linfáticos y el hígado, y éstas, alternadamente, son activadas para producir el IFN tipo I que media la inmunidad antiviral ${ }^{65}$.

Durante el brote de HPAI H5N1 en Hong-Kong en $1997^{6}$, las manifestaciones clínicas eran de inicio rápido de estado gripal que conducía a la enfermedad respiratoria severa y finalmente a la disfunción multiorgánica, revelando el hecho de que este virus tiene

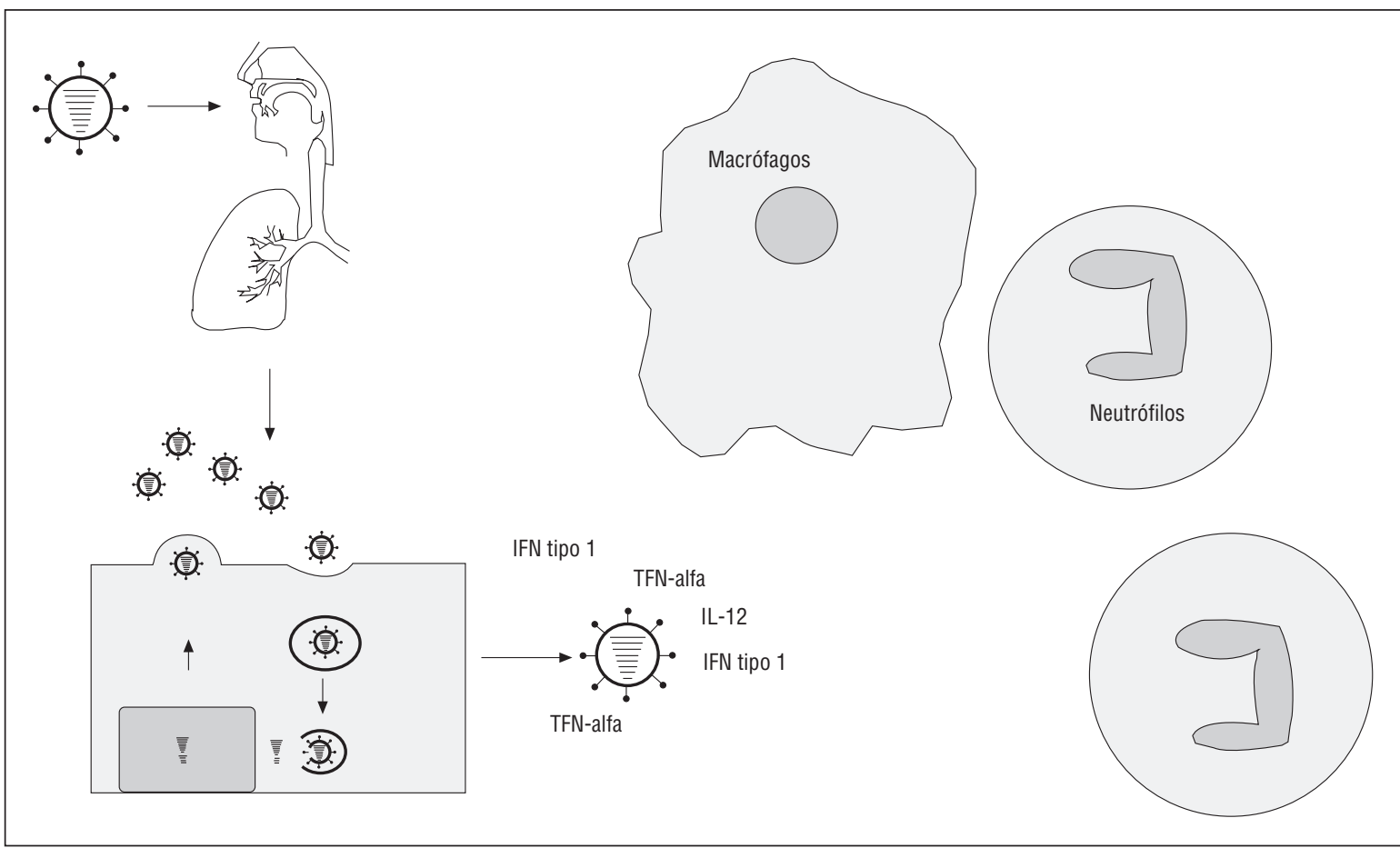

Figura 3. Acontecimientos patógenos durante la infección aviar de la gripe H5N1. Después de ser introducido en el epitelio respiratorio, el virus repliega y lisa la célula huésped. Ésta, alternamente, atraerá la respuesta inflamatoria. Los macrófagos, así como los neutrófilos, liberan inmediatamente citoquinas antivirales y promueven más adelante la quimiotaxis del linfocito. IFN: interferón; IL: interleucina; TNF: factor de necrosis tumoral. 


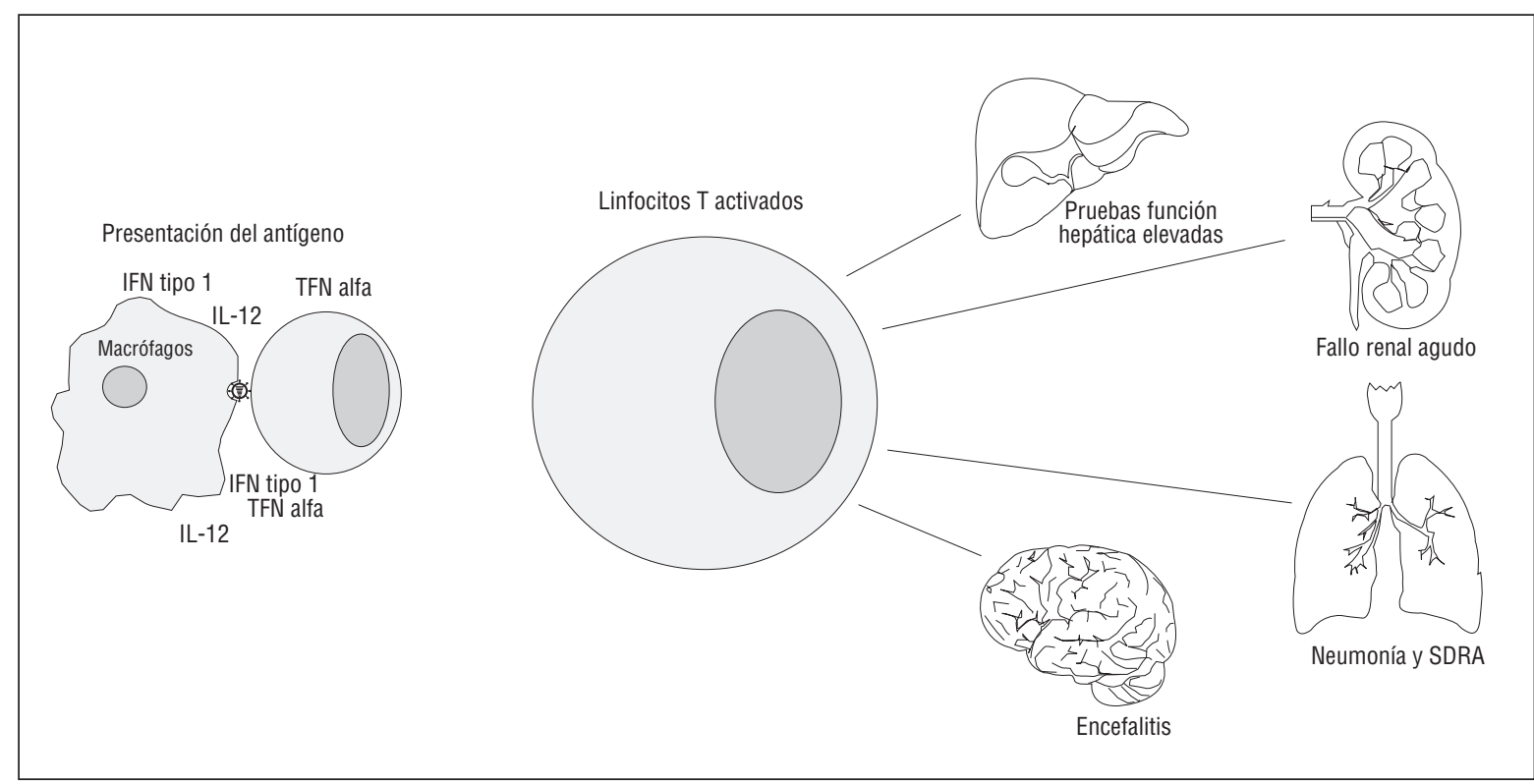

Figura 4. Después del inicio agudo de la infección. Los macrófagos y los neutrófilos están presentes desde muy pronto en el proceso de la in flamación. Algunos días después del daño inicial los macrófagos presentan los antígenos al linfocito Tingenuamente. La activación entonces desarrolla una respuesta exagerada que afecta al hígado, los riñones, el pulmón y, en algunos casos, causa encefalitis. IL-12: interleucina 12; SDRA: síndrome de distrés respiratorio agudo.

no solamente la capacidad de infectar el pulmón o el tejido intestinal, sino que puede provocar una infección diseminada a cambio (por ejemplo, tejido linfoide, hígado y bazo) ${ }^{64,66}$.

La inmunorrespuesta secundaria es una respuesta específica dirigida contra las proteínas virales de la capa y las proteínas internas ${ }^{67}$. Está dirigida principalmente por la producción de células B de anticuerpos específicos y por efectos citotóxicos de los linfocitos CD-8 con regulación adicional desde los linfocitos CD-4 helper ${ }^{68,69}$.

La reinfección viral provocada por el contacto con el virus vía mucosa nasal dará lugar inmediatamente a la réplica viral y a la lisis del epitelio de la vía aérea, de forma que más partículas virales estarán disponibles para el reconocimiento por linfocitos CD-8 citotóxicos, los cuales proliferarán y emigrarán al epitelio infectado y a los linfáticos de la zona respiratoria, generalmente una semana después de que se haya hecho el contacto ${ }^{70-73}$. Esto, alternamente, permite que los linfocitos CD-8 liberen citoquinas antivirales en los lugares infectados. Dos mediadores especiales en la lisis de células infectadas son liberados por los linfocitos CD-8, cuyos gránulos contienen perforinas y granzimas $^{67,74}$.

Los epítopes (partes de una molécula que son reconocidas por el sistema inmune) virales múltiples y el antígeno que presentan las células en los sitios infectados son los que están a cargo de dar la orden de ataque para desbloquear los gránulos de los linfocitos CD-8, permitiendo a las células T citotóxicas actuar en lugares específicos, entre ellos el tracto respiratorio superior y el tejido pulmonar, conduciendo a una reacción localizada ${ }^{75,76}$.

\section{MANIFESTACIONES CLÍNICAS}

El curso clínico de la gripe fue documentado por primera vez en un niño que murió tras sufrir el síndrome de Reye en Hong-Kong en $1997^{77}$. La gripe como enfermedad requiere de fiebre aguda (temperatura $>38,0^{\circ} \mathrm{C}$ ), así como tos o garganta dolorida en ausencia de otro diagnóstico ${ }^{28}$. El dolor de cabeza, las mialgias, el malestar general y la rinitis también suelen estar presentes ${ }^{64}$. Los pacientes que sufren la gripe humana generalmente manifiestan conjuntivitis e infección superior de la zona respiratoria, pero a diferencia de ella, la gripe aviar no presenta generalmente la afectación conjuntival ${ }^{78}$.

La mayoría de los casos humanos reportados habían evidenciado la exposición a la especie aviar que manifestaba la enfermedad, por ejemplo aves de corral enfermas $^{79}$. La fiebre apareció en casi todos los pacientes así como la sintomatología respiratoria baja, consistente principalmente en tos y disnea que progresaron seguidamente a un franco distrés respiratorio $^{80,81}$.

La gripe como enfermedad puede ser indistinguible de otras enfermedades respiratorias y febriles ${ }^{82}$. En 1997, en Hong-Kong, hasta el 61\% desarrolló neumonía ${ }^{83}$, pero también se han descrito diarreas, vómitos y dolor abdominal, así como dolor pleurítico y epistaxis ${ }^{84}$. En 1997 la infección afectó a la mayoría de las personas entre 9,5 y 22 años $^{25}$ (tabla 2).

En algunas series publicadas, el fallo respiratorio y el síndrome de distrés respiratorio agudo (SDRA) estaba presente en más del $75 \%$ de los pacientes ${ }^{30}$.

También se han descrito casos atípicos: en Tailandia una mujer de 39 años de edad presentó durante 
TABLA 2. Síntomas principales de presentación en el sudeste de Asia

\begin{tabular}{|lc|}
\hline \multicolumn{2}{|c|}{ Sudeste de Asia (HK, T, V, HCMC, C) } \\
\hline Población & 59 \\
& \\
Fiebre & $98 \%$ \\
Tos & $88 \%$ \\
Disnea & $57 \%$ \\
Esputo & $35 \%$ \\
Diarrea & $32 \%$ \\
Dolor de garganta & $28 \%$ \\
Rinorrea & $27 \%$ \\
Mialgias & $22 \%$ \\
Vómitos & $18 \%$ \\
Dolor abdominal & $15 \%$ \\
Cefaleas & $15 \%$ \\
\hline
\end{tabular}

C: Camboya; HCMC: ciudad Ho Chi Minh; HK: Hong Kong; T: Tailandia; V: Vietnam. Fuente: The Writing Committee of the World Health Organization (WHO) Consultation on Human Influenza A/H5.
TABLA 3. Síntomas principales de presentación en el sudeste de Asia. Complicaciones principales durante la hospitalización

\begin{tabular}{|ll|}
\hline \multicolumn{2}{|c|}{ (HK, T, V, HCMC, C) } \\
\hline Población & 59 \\
& \\
SDRA & $69 \%$ \\
Elevación de enzimas hepáticas & $52 \%$ \\
Leucopenia & $45 \%$ \\
Trombocitopenia & $27 \%$ \\
Disfunción renal & $20 \%$ \\
Insuficiencia cardiaca & $11 \%$ \\
Derrame pleural & $5 \%$ \\
Síndrome de Reye & $1 \%$ \\
Hemorragia gastrointestinal & $1 \%$ \\
\hline
\end{tabular}

C: Camboya; HCMC: ciudad Ho Chi Minh; HK: Hong Kong; SDRA: síndrome de distress respiratorio agudo; $\mathrm{T}$ : Tailandia; V: Vietnam.

Fuente: The Writing Committee of the World Health Organization (WHO) Consultation on Human Influenza A/H5.

morrágicas. No se observaron cuerpos virales de inclusión ${ }^{30}$.

Uiprasertkul et $\mathrm{al}^{87}$ encontraron en una autopsia que el pulmón mostró proliferación y daño alveolar, neumonía intersticial y bronquiolitis. Los neumocitos indicaron hiperplasia marcada. También se encontró que el paciente tenía infección concomitante por hongos, específicamente aspergillosis. Los órganos linfoides, como los nódulos linfáticos, el bazo y la médula, mostraron hiperplasia histiocítica leve ${ }^{87}$.

Experimentos realizados en gatos por Kuiken et al mostraban que el pulmón de un cat fed, infectado por un polluelo inoculado con el virus H5N1, tenía focos múltiples de consolidación, que consistían histológicamente en daño alveolar difuso, con la expresión de gripe en tejidos inflamados y demostrados por inmunohistoquímica ${ }^{88}$. Ungchusak et al publican un caso en el que se sugiere la transmisión entre seres humanos. En ese estudio la madre de un paciente con gripe aviar confirmada (H5N1) permaneció en su cabecera durante varios días y tras ello desarrolló fiebre y cefaleas; fue ingresada en el hospital con disnea severa y leucopenia y falleció tres días más tarde. En la autopsia, el análisis immunohistoquímico de la pieza reveló neumonitis intersticial y sólo una célula epitelial contenía cuerpos intranucleares de la gripe aviar $\mathrm{H} 5 \mathrm{~N} 1^{34}$.

Alrededor del 70\% de los pacientes infectados desarrollará manifestaciones respiratorias y la mayoría de ellos tendría una imagen representativa de la enfermedad si se le realizase una simple radiografía de tórax ${ }^{25}$. Casi todos los pacientes tienen cambios radiográficos que incluyen infiltrados difusos, multifocales o parcheados, infiltrados intersticiales y segmentos de consolidación lobular con broncograma aéreo ${ }^{64}$. En un estudio, las anormalidades radiográficas estaban presentes una media de 7 días después del inicio de la fiebre (rango: 3-17) ${ }^{25}$.

\section{DETECCIÓN}

Según las recomendaciones de la Organización Mundial de la Salud, la muestra óptima para la detec- 
TABLA 4. Características principales de la prueba rápida de la detección del antígeno

\begin{tabular}{|c|c|}
\hline \multicolumn{2}{|c|}{ Detección rápida del antígeno } \\
\hline Prueba & Característica principal \\
\hline Prueba para la gripe cercana al paciente & Comercialmente disponible \\
\hline Análisis inmunofluorescente & Identifica la gripe A y partículas virales de B \\
\hline Inmunoanálisis enzimático & Para la nucleoproteína de la gripe A NP \\
\hline \multicolumn{2}{|c|}{$\begin{array}{l}\text { Detección del virus en muestras clínicas o cultivos de célula } \\
\text { Las muestras clínicas se deben recoger cuanto antes después del inicio de los síntomas } \\
\text { Resultados obtenidos en 15-30 minutos }\end{array}$} \\
\hline
\end{tabular}

ción del virus de la gripe A es un aspirado nasofaríngeo obtenido en el plazo de tres días desde el inicio de los síntomas. Hay tres métodos principales para detectar partículas o la infección viral en un individuo determinado ${ }^{89}$ : la detección del antígeno, el cultivo del virus y el análisis de la reacción en cadena de la polimerasa (en tiempo real) ${ }^{89}$ (tablas 4,5 y 6 ).

Woo et al encontraron en 1997 que el diagnóstico rápido de infecciones respiratorias virales es rentable y reduce el tiempo de hospitalización ${ }^{90}$. El diagnóstico rápido es de confianza y útil en el seguimiento médico de pacientes afectados por la gripe aviar H5N1.

\section{TRATAMIENTO. EXPERIENCIAS ACTUALES CON ANTIVIRALES}

Los antivirales más potentes y eficaces son el zanamivir y el oseltamivir. Estos fármacos son eficaces frente al amplio espectro de la gripe A y de los virus $\mathrm{B}$, e incluyen los 9 subtipos de la neuraminidasa en la especie aviar ${ }^{91}$.

Según lo publicado por Nicholson, los amantadanes (como amantadine y rimantadine) son eficaces para el tratamiento de la infección aguda de la gripe A si la terapia antivírica se comienza en el plazo de las primeras 24 horas tras el inicio de la enfermedad, reduciendo la fiebre y los síntomas ${ }^{92}$.

Los inhibidores de la neuraminidasa son útiles en el tratamiento y la quimioprofilaxis en la gripe aviar y su eficacia está probada con la reducción de síntomas y complicaciones, aunque es menos potencial frente a cepas resistentes emergentes y para combatir la gripe que emerge por cepas aviares, por ejemplo la H5 y la H9, para las cuales la vacunación es inasequible ${ }^{93}$.

Desafortunadamente, según lo recomendado por Balicer et al, la cantidad de medicación eficaz para una pandemia es muy pequeña y se recomienda co- menzar un almacenaje de oseltamivir para contraatacar un brote pandémico posible e inminente de la gripe aviar altamente patógena $\mathrm{H} 5 \mathrm{~N} 1^{94}$. Ejemplos de países que están almacenando ya oseltamivir son Finlandia ${ }^{95}$ e Inglaterra ${ }^{96}$.

\section{PREVENCIÓN Y VACUNAS}

Las vacunas existentes corresponden a tres grupos principales: virus entero, productos divididos y antígenos de superficie ${ }^{36}$. Se obtiene una eficacia protectora del 70-95\% en adultos jóvenes sanos cuando hay un buen encuentro antigénico entre la vacuna y las cepas que circulan ${ }^{97}$, una reducción del $19-63 \%$ en la hospitalización para la neumonía y la gripe, del 17$39 \%$ en todas las condiciones respiratorias y del 27$75 \%$ en todas las causas de mortalidad ${ }^{36}$.

El hecho de que los virus de la gripe tengan la capacidad de infectar los huevos de gallinas es utilizado ventajosamente para la producción de partículas virales en un ambiente controlado. Desafortunadamente, tanto los subtipos $\mathrm{H} 5$ como $\mathrm{H} 7$ son letales para alguna especie aviar; de hecho, el cultivo viral de $\mathrm{H} 5$ y $\mathrm{H} 7$ en embriones del pollo es casi imposible debido a la letalidad en éstos ${ }^{98}$.

Después del brote de 1997 de la gripe aviar H5N1 en Hong-Kong, Reino Unido y Holanda prepararon vacunas $^{99}$. Ambos atenuados, H5N1 y H9N2, son virus recombinantes adaptados al frío que han sido generados para no ser patógenos en modelos de mamíferos y de pollos ${ }^{100}$.

La vacuna adaptada al frío, consistente en virus recombinantes, se entrega con una dosis más grande de partículas virales al tejido linfoide bronquial que la vacuna inactivada, dando por resultado una respuesta inmunológica más compleja y expandida ${ }^{91}$. Esto incluye anticuerpo sérico (inmunoglobulina [Ig] G, IgA, IgM) elevado o similar tanto a la hemaglutinina y la

TABLA 5. Características principales de la prueba del cultivo del virus

\begin{tabular}{|l|}
\hline \multicolumn{1}{|c|}{ Cultivo viral } \\
\hline Técnica sensible \\
Disponibilidad del virus para la identificación y su caracterización \\
Resultados en 2-10 días \\
La identificación por la inmunofluorescencia de los cultivos de célula o el análisis de la hemaglutinación-inhibición del cultivo de célula \\
es requerido \\
Prueba de la susceptibilidad del fármaco \\
Puede ser utilizado para la producción y las pruebas de vacunas
\end{tabular}


TABLA 6. Características principales de la prueba de la reacción en cadena de la polimerasa

\begin{tabular}{|l|}
\hline \multicolumn{1}{|c|}{ Reacción en cadena de la polimerasa } \\
\hline Técnica de gran alcance para la identificación de los genomas del virus de la gripe \\
Detección de hemaglutinina y de nucleoproteína 1 \\
Los resultados están disponibles pasadas algunas horas de cualquier muestra como una torunda o de cultivos de células infectadas \\
\hline
\end{tabular}

neuraminidasa, más los anticuerpos neutralizados y la respuesta secretora mucosa local de IgA mayor que la vacuna parenteral ${ }^{91,101}$, y una reducción de la cantidad y de la frecuencia del vertido viral en comparación con la vacuna inactivada tras la infección ${ }^{34}$.

\section{Declaración de conflicto de intereses}

Los autores no divulgan ningún conflicto de interés en la preparación de este manuscrito.

\section{BIBLIOGRAFÍA}

1. Grijalva CG. Estimating influenza hospitalizations among children. Emerg Infect Dis. 2006;12:103-9.

2. Jin XW, Mossad SF. Avian influenza: an emerging pandemic threat. Clev Clin J Med. 2005;71:1129-34.

3. Kilbourne ED. Influenza pandemics: can we prepare for the unpredictable? Viral Immunol. 2004:17:350-7.

4. Palese P. Influenza: old and new threats. Nat Med. 2004;10: S82-7.

5. Taubenberger JK, Morens D. 1918 Influenza: the mother of all pandemics. Emerg Infect Dis. 2006;12:15-22.

6. Chan PK. Outbreak of avian influenza A (H5N1) virus infection in Hong Kong in 1997. Clin Infect Dis. 2002;34:S58-64.

7. Webster R, Peiris M, Chen H, Guan Y. H5N1 outbreaks and enzootic influenza. Emerg Infect Dis. 2006;12:3-8.

8. The World Health Organization Global Influenza Program Surveillance Network: Evolution of H5N1 avian influenza viruses in Asia. Emerg Infect Dis. 2005;11:1516-21.

9. Epidemic and Pandemic Alert and Response (EPR). Cumulative Number of Confirmed Human Cases of Avian Influenza A/(H5N1) Reported to WHO: http://www.who.int/csr/ disease/ avian_influenza/country/cases_table_2006_11_29/en/index.html (consultado 20/12/2006).

10. Wong SS, Yuen KY. Avian influenza virus infections in humans. Chest. 2006;129:156-68.

11. Murphy BR, Webster RG. Orthomyxoviruses. En: Fields BN, Knipe DM, Howley PM, editores. Virology. Vol 1. Philadelphia: Lippincott-Raven; 1996. pp. 1397-445.

12. Avian influenza ("bird flu") - Fact sheet. Disponible en: http://www.who.int/mediacentre/factsheets/avian_influenza/en/ (consultado 18/10/2006)

13. Johnson NP, Mueller J. Updating the accounts: global mortality of the 1918-1920 "Spanish" influenza pandemic. Bull Hist Med. 2002;76:105-15.

14. Pérez D, Sorrell E, Donis RO. Avian influenza an omnipresent pandemic threat. Pediatr Infect Dis J. 2005;24 Suppl 11:S20816.

15. Taubenberger JK, Reid AH, Krafft AE, Bijwaard KE, Fanning TG. Initial genetic characterization of the 1918 "Spanish" influenza virus. Science. 1997;275:1793-6.

16. Reid AH, Fanning TG, Hultin JV, Taubenberger JK. Origin and evolution of the 1918 "Spanish" influenza virus hemagglutinin gene. Proc Natl Acad Sci U S A. 1999;96:1651-6.

17. Ito T, Couceiro JN, Kelm S, Baum LG, Krauss S, Castrucci MR, et al. Molecular basis for the generation in pigs of influenza A viruses with pandemic potential. J Virol. 1998;72:7367-73.

18. Simonsen L, Clarke MJ, Schonberger LB, Arden NH, Cox NJ, Fukuda K. Pandemic versus epidemic influenza mortality: a pattern of changing age distribution. J Infect Dis. 1978;178:53-60.
19. Taubenberger JK, Reid AH, Lourens RM, Wang R, Jin G, Fanning TG. Characterization of the 1918 influenza virus polymerase genes. Nature. 2005;437:889-93.

20. Bean W, Schell M, Katz J, Kawaoka Y, Naeve C, Gorman $\mathrm{O}$, et al. Evolution of the $\mathrm{H} 3$ influenza virus hemagglutinin from human and nonhuman hosts. J Virol. 1992;66:1129-38.

21. Turner D, Wailoo A, Nicholson K, Cooper N, Sutton A, Abrams K. Systematic review and economic decision modelling for the prevention and treatment of influenza A and B. Health Technol Assess. 2003. 7:iii-iv, xi-xiii, 1-170.

22. Thompson WW, Shay DK, Weintraub E, Brammer L, Cox $\mathrm{N}$, Anderson LJ, et al. Mortality associated with influenza and respiratory syncytial virus in the United States. JAMA. 2003;289: 179-86.

23. Simonsen L, Fukuda K, Schonberger LB, Cox NJ. The impact of influenza epidemics on hospitalizations. J Infect Dis. 2000; $181: 831-7$

24. Mounts AW, Kwong H, Izurieta HS, Ho Y, Au T, Lee M, et al. Case-control study of risk factors for avian influenza $\mathrm{A}$ (H5N1) disease, Hong Kong 1997. J Infect Dis. 1999;180:505-8.

25. The Writing Committee of the World Health Organization (WHO) Consultation on Human Influenza A/H5. Avian influenza A (H5N1) infection in humans. N Engl J Med. 2005;353:1374-85.

26 Katz JM, Lim W, Bridges CB, Rowe T, Hu-Primmer J, Lu X, et al. Antibody response in individuals infected with avian influenza A (H5N1) viruses and detection of anti-H5 antibody among household and social contacts. J Infect Dis. 1999;180:1763-70.

27. Tiensin T, Chaitaweesub P, Songserm T, Chaisingh A, Hoonsuwan W, Buranathai C, et al. Highly Pathogenic Avian Influenza H5N1, Thailand, 2004. Emerg Infect Dis. 2005;11:1664-72.

28. Chen H, Deng G, Li Z, Tian G, Li Y, Jiao P, et al. The evolution of H5N1 influenza viruses in ducks in southern China. Proc Natl Acad Sci U S A. 2004;101:10452-7.

29. National Economic and Social Development Board. Analysis of avian influenza epidemics' impacts on the Thai economy in 2004. Disponible en: http://www.nesdb.go.th/econSocial/ macro/Outlook_data/econ_outlook_q4_46/03.pdf (consultado 22/12/2006).

30. Chotpitayasunondh T, Ungchusak K, Hanshaoworakul W, Chunsuthiwat S, Sawanpanyalert P, Kijphati R, et al. Human disease from influenza A (H5N1), Thailand, 2004. Emerg Infect Dis. 2005;11:201-9.

31. Hien TT, Liem NT, Dung NT, San LT, Mai PP, Chau N, et al. Avian influenza A (H5N1) in 10 patients in Vietnam. N Engl J Med. 2004;350:1179-88.

32. Liem NL, Lim W; World Health Organization International Avian Influenza Investigation Team, Vietnam. Lack of H5N1 avian influenza transmission to hospital employees, Hanoi, 2004. Emerg Infect Dis. 2005;11:210-5.

33. Uyeki T, Chong YH, Katz JM, Lim W, Ho YY, Wang SS, et al. Lack of evidence for human-to-human transmission of avian influenza A (H9N2) viruses in Hong Kong, China, 1999. Emerg Infect Dis. 2002;8:154-9.

34. Ungchusak K, Auewarakul P, Dowell SF, Kitphati R, Auwanit W, Puthavathana P, et al. Probable person-to-person transmission of avian influenza A (H5N1). N Engl J Med. 2005;352:333-40.

35. Wu T, Hu LM. Avian influenza. Chang Gung Med J. 2005; 28:753-7.

35. Ulmanen I, Broni BA, Krug RM. Role of two of the influenza virus core $\mathrm{P}$ proteins in recognizing cap 1 structures (m7GpppNm) on RNAs and in initiating viral RNA transcription. Pro Nati Acad Sci U S A. 1981;78:7355-9.

36. Stephenson I, Nicholson KG, Wood JM, Zambon MZ, Katz JM. Confronting the avian influenza threat: vaccine development for a potential pandemic. Lancet Infect Dis. 2004;4:499-509. 
37. Webster RG. Predictions for future human influenza pandemics. J Infect Dis. 1997;176:S14-9.

38. Kaye D, Pringle CR. Avian influenza viruses and their implication for human health. Clin Infect Dis. 2005;40:108-12.

39. Couceiro JN, Paulson JC, Baum LG. Influenza virus strains selectively recognize syaliloligosaccharides on human respiratory epithelium: the role of the host cell in selection of hemagglutinin receptor specificity. Virus Res. 1993;29:155-65.

40. Rott $R$. The pathogenic determinant of influenza virus. Vet Microbiol. 1992;33:303-10.

41. Hatta M, Gao P, Halfmann P, Kawaoka Y. Molecular basis for high virulence of Hong Kong H5N1 influenza A viruses. Science. 2001;293:1840-2.

42. Lewis D. Avian flu to human influenza. Annu Rev Med. 2006;57:139-54

43. Claas EC, Osterhaus AD, van Beek R, De Jong JC, Rimmelzwaan GF, Senne DA, et al. Human influenza A H5N1 virus related to a highly pathogenic avian influenza virus. Lancet. 1998;351:472-7.

44. Hilleman MR. Realities and enigmas of human viral influenza: pathogenesis, epidemiology and control. Vaccine. 2002;20: 3068-87.

45. Chanturiya AM, Basanez C, Schubert U, Henklein P, Yewdell JW, Zimmerberg J, et al. PB1-F2, an influenza A virus proapoptotic mitochondrial protein, creates variable size pores in planar lipids membranes. J Virol. 2004;78;6304-12.

46. Zambon MC. The pathogenesis of influenza in humans. Rev Med Virol. 2001;11:227-41.

47. Salgado CD, Farr BM, Hall KK, Hayden FG. Influenza in the acute hospital setting. Lancet Infect Dis. 2002;2:145-55.

48. Bridges CB, Kuehnert MJ, Hall CB. Transmission of influenza: implications for control in health care settings. Clin Infect Dis. 2003;37:1094-101.

49. Alexander DJ. A review of avian influenza in different bird species. Vet Microbiol. 2000;74:3-13.

50. Webster RG, Bean WJ, Gorman OT, Chambers TM, Kawaoka Y. Evolution and ecology of influenza A viruses. Microbiol Rev. 1992;56:152-79.

51. Liu J, Xiao H, Lei F, Zhu Q, Qin K, Zhang XW, et al. Highly pathogenic H5N1 influenza virus infection in migratory birds. Science. 2005;309:1206.

52. World Organization for Animal Health. Disponible en: http://www.oie.int/downld/AVIAN\%20INFLUENZA/A_AIAsia.htm (consultado 21/12/2006).

53. Hulse-Post DJ, Sturm-Ramirez KM, Humberd J, Seiler P, Govorkova EA, Krauss S, et al. Role of domestic ducks in the propagation and biological evolution of highly pathogenic H5N1 influenza viruses in Asia. Proc Natl Acad Sci U S A. 2005;102: 10682-7.

54. Chotpitayasunondh $T$, Lochindarat $S$, Srisan $P$, et al. Cases of influenza A (H5N1) - Thailand, 2004. MMWR. 2004;53:100-3.

55. Claas ECJ, Osterhaus AD. New clues to the emergence of flu pandemics. Nat Med. 1998;4:1122-3.

56. Bridges CB, Katz JM, Seto WH. Risk of influenza A (H5N1) infection among health care workers exposed to patients with influenza A (H5N1), Hong Kong. J Infect Dis. 2000;181:3448.

57. Lee SY, Mak KH, Saw TA. The avian flu (H5N1): one year on. Department of Health, Hong Kong Special Administrative Region of China. Pub Health Epid Bull. 1999;8:1-7.

58. Cheung CY, Poon LLM, Lau AS, Luk W, Lau YL, Shortridge $\mathrm{KF}$, et al. Induction of proinflammatory cytokines in human macrophages by influenza A H5N1 viruses: a mechanism for the unusual severity of human disease? Lancet. 2002;360:1831-7.

59. Bosch FX, Orlich M, Klenk HD, Rott R. Proteolytic cleavage of influenza virus haemagglutinins: primary structure of the connecting peptide between HA1 and HA2 determines proteolytic cleavability and pathogenicity of avian influenza viruses. Virology. 1981;113:725-35.

60. Lund JM, Alexopoulou L, Sato A, Karow M, Adams NC, Gale NW, et al. Recognition of single-stranded RNA viruses by Toll-like receptor 7. Proc Natl Acad Sci U S A. 2004;101:5598603.

61. Guillot L, Le Goffic R, Bloch S, Escriou N, Akira S, Chignard M, et al. Involvement of toll-like receptor 3 in the im- mune response of lung epithelial cells to double-stranded RNA and influenza A virus. J Biol Chem. 2005;280:5571-80.

62. Seo SH, Webster RG. Tumor necrosis factor alpha exerts powerful anti-influenza virus effects in lung epithelial cells. J Virol. 2002;76:1071-6.

63. Boyd M, Clezy K, Lindley R, Pearce R. Pandemic influenza: clinical issues. Med J Aust. 2006;185 Suppl 10:S44-7.

64. Yuen KY, Chan PK, Peiris M, Tsang DN, Que TL, Shortridge KF, et al. Clinical features and rapid viral diagnosis of human disease associated with avian influenza A H5N1 virus. Lancet. 1998;351:467-71.

65. Diebold SS, Montoya M, Unger H, Alexopoulou L, Roy P Haswell LE, et al. Viral infection switches nonplasmacytoid dendritic cells into high interferon producers. Nature. 2003:424:324-8.

66. Maines TR, Lu XH, Erb SM, Edwards L, Guarner J, Greer PW, et al. Avian influenza (H5N1) viruses isolated from humans in Asia in 2004 exhibit increased virulence in mammals. J Virol. 2005;79:11788-800.

67. Thomas PG, Keating R, Husle-Post DJ, Doherty CP. Cellmediated protection infection in influenza infection. Emerg Infect Dis. 2006; $12: 48-54$.

68. Turner SJ, Kedzierska K, La Gruta NL, Webby R, Doherty $\mathrm{P}$. Characterization of CD8+ T cell repertoire diversity and persistente in the influenza A virus model of localized, transient infection. Semin Immunol. 2004;16:179-84.

69. Swain SL, Dutton RW, Woodland DL. T-cell responses to influenza virus infection: effector and memory cells. Viral Immunol. 2004; 17:197-209.

70. Lawrence CW, Braciale TJ. Activation, differentiation, and migration of naive virus-specific $\mathrm{CD} 8+\mathrm{T}$ cells during pulmonary influenza virus infection. J Immunol. 2004;173:1209-18.

71. Tripp RA, Sarawar SR, Doherty PC. Characteristics of the influenza virus-specific CD8+ T cell response in mice homozygous for disruption of the H-2lAb gene. J Immunol. 1995;155: 2955-9.

72. Cerwenka A, Morgan TM, Dutton RW. Naive, effector, and memory CD8 T cells in protection against pulmonary influenza virus infection: homing properties rather than initial frequencies are crucial. J Immunol. 1999;163:5535-43.

73. Lawrence CW, Ream RM, Braciale TJ. Frequency, specificity, and sites of expansion of CD8+ T cells during primary pulmonary influenza virus infection. J Immunol. 2005;174:5332-40.

74. Topham DJ, Tripp RA, Doherty PC. CD8+ T cells clear influenza virus by perforin or Fas-dependent processes. J Immunol. 1997; 159:5197-200.

75. Walker JA, Molloy SS, Thomas G, Sakaguchi T, Yoshida T, Chambers TM, et al. Sequence specificity of furin, a proprotein processing endoprotease, for the hemagglutinin of a virulent avian influenza virus. J Virol. 1994;68:1213-8.

76. Walker JA, Sakaguchi T, Matsuda Y, Yoshida T, Kawaoka Y. Location and character of the cellular enzyme that cleaves the hemagglutinin of a virulent avian influenza virus. Virology. 1992; 190:278-87.

77. de Jong JC, Claas ECJ, Osterhaus AD. A pandemic warning. Nature. 1997;389:554.

78. Fouchier RAM, Schneeberger PM, Rozendaal FW, Broekman JM, Kemink SA, Munster V, et al. Avian influenza A virus (H7N7) associated with human conjunctivitis and a fatal case of acute respiratory distress syndrome. Proc Natl Acad Sci USA. 2004;101:1356-61.

79. Bridges CB, Lim W, Hu-Primmer J, Sims L, Fukuda K, Mak KH, et al. Risk of influenza A (H5N1) infection among poultry workers, Hong Kong, 1997-1998. J Infect Dis. 2002;185: 1005-10.

80. Chan PK. Outbreak of avian influenza $A(H 5 N 1)$ virus in fection in Hong Kong in 1997. Clin Infect Dis. 2002;34:S58-S64.

81. Schultsz C, Dong VC, Chau NV, Le NT, Lim W, Thanh TT, et al. Avian influenza H5N1 and healthcare workers. Emerg Infect Dis. 2005;11:1158-9.

82. O'Brien MA, Uyeki TM, Shay DK, Thompson WW, Kleinman K, McAdam A, et al. Incidence of outpatient visits and hospitalizations related to influenza in infants and young children. Pediatrics. 2004; 113:585-93.

83. Bender C, Hall H, Huang J, Klimov A, Cox N, Hay A, et al Characterization of the surface proteins of influenza A H5N1 viru- 
ses isolated from humans in 1997-1998. Virology. 1999;254:11523.

84. Tam JS. Influenza A (H5N1) in Hong Kong: an overview. Vaccine. 2002;20 Suppl 2:S77-81.

85. Apisarnthanarak A, Kitphati R, Thonghubeth K, Patoomanunt $\mathrm{P}$, Anthanont $\mathrm{P}$, Auwanit W, et al. Atypical avian influenza (H5N1). Emerg Infect Dis. 2004;10:1321-4.

86. de Jong M, Van Cam B, Qui PT, Hien VM, Thanh TT, Hue NB, et al. Fatal avian influenza A (H5N1) in a child presenting with diarrhea followed by coma. N Engl J Med. 2005;352:686-91.

87. Uiprasertkul M, Puthavathana P, Sangsiriwut K, Pooruk P, Srisook K, Peiris M, et al. Influenza A H5N1 Replication Sites in Humans. Emerg Infect Dis. 2005;11:1036-41.

88. Kuiken $T$, Rimmelzwaan $G$, van Riel D, van Amerongen $G$, Baars M, Fouchier R, et al. Avian H5N1 influenza in cats. Science. 2004;306:241.

89. World Health Organization. Recommended laboratory tests to identify avian influenza A virus in specimens from humans. WHO Geneva June 2005. Disponible en: www.who.int/csr/disease/avian_influenza/guidelines/avian_labtests2.pdf (consultado 23/12/2006).

90. Woo PC, Chiu SS, Seto WH, Peiris M. Cost-effectiveness of rapid diagnosis of viral respiratory tract infections in pediatric patients. J Clin Microbiol. 1997;35:579-81.

91. Stephenson I, Nicholson KG. Influenza: vaccination and treatment. Eur Respir J. 2001;17:1282-93.

92. Nicholson KG, Wiselka MJ. Amantadine for influenza A. BMJ. 1991;302:425-6.
93. Webster R. Efficacy of oseltamivir on H5N1 and H9N2 influenza viruses. Second International Symposium on Influenza and other Respiratory viruses. 1999, Grand Cayman, British West Indies.

94. Balicer RD, Huerta M, Davidovitch N, Grotto I. Cost-Benefit of Stockpiling Drugs for Influenza Pandemic. Emerg Infect Dis. 2005;11:1280-2.

95. Reuters Health Information. Finland says it's to buy stocks of Roche's Tamiflu. Mar 10, 2005. Disponible en: http://www.influenza.com/ (consultado 20/12/2006).

96. Coombes R. UK stocks up on antiviral drug to tackle flu outbreak. BMJ. 2005;330:495.

97. Meiklejohn G, Eickhoff TC, Graves P. Antigenic drift and efficacy of influenza virus vaccines. J Infect Dis. 1978;138:618-24.

98. Takada A, Kuboki N, Okazaki K, Ninomiya A, Tanaka H, Ozaki $\mathrm{H}$, et al. Avirulent avian influenza virus as a vaccine strain against a potential human pandemic. J Virol. 1999;73:8303-7.

99. Wood JM, Major D, Daly J, Newman RW, Dunleavy U, Nicolson C, et al. Vaccine against H5N1 influenza. Vaccine. 2000; 18:579-80.

100. Li S, Liu C, Klimov A, Subbarao K, Perdue ML, Mo D, et al. Recombinant influenza A virus vaccines for the pathogenic human A/Hong Kong/97 (H5N1) viruses. J Infect Dis. 1999;179: 1132-8.

101. Belshe RB, Gruber WC, Mendelman PM, Mehta HB, Mahmood K, Reisinger K, et al. Correlates of immune protection induced by live attenuated cold adapted trivalent intranasal influenza virus vaccine. J Inf Dis. 2000;181:1133-7. 